\title{
ANTEPROJETO DE HABITAÇÃO DE INTERESSE SOCIAL SOB AS DIRETRIZES EM CONFORTO TÉRMICO PARA A CIDADE DE TRIUNFO-PARAÍBA
}

\author{
PRELIMINARY PROJECT OF SOCIAL INTEREST HOUSING UNDER \\ THE GUIDELINES OF THERMAL COMFORT FOR THE CITY OF \\ TRIUNFO - PARAÍBA
}

\author{
Pedro Jorge Gonçalves Claudino ${ }^{1}$ \\ Camilla Furtado de Figueiredo ${ }^{2}$ \\ Ezio Luiz Martins Simões ${ }^{3}$ \\ Mirela Davi de Melo ${ }^{4}$ \\ Rafael Costa de Carvalho Abrantes ${ }^{5}$ \\ Marjorie Maria Abreu Gomes de Farias ${ }^{6}$
}

\footnotetext{
${ }^{1}$ Graduanda em Arquitetura e Urbanismo pela Faculdade Santa Maria - FSM;

${ }^{2}$ Graduada em Arquitetura e Urbanismo pela Universidade Federal da Paraíba (2014), pós-graduada Habitação Social e Direito à Cidade pela Universidade Federal da Bahia (2016), pós-graduada em Arquitetura, Gestão e Construção de Edificações Sustentáveis pela Faculdade Unyleya (2016), mestre em Engenharia de Energias Renováveis com dissertação voltada para a pesquisa de alternativas de materiais de construção sustentáveis pela Universidade Federal da Paraíba (2017). Atualmente, é docente da Faculdade Santa Maria (FSM) e no Centro Universitário de João Pessoa (UNIPE), ambos no curso de Arquitetura e Urbanismo.

${ }_{3}^{3}$ Possui graduação em Arquitetura e Urbanismo pelo Centro Universitário de João Pessoa (2012) e mestrado pela Universidade Federal da Paraíba (PPGAU-UFPB). Atualmente é professor nas Faculdades Integradas de Patos-PB (FIP), mas também já trabalhou como professor na Faculdade Santa Maria de Cajazeiras-PB (FSM). Atua principalmente nos seguintes temas: requalificação urbana, bioclimatismo, projeto participativo e arquitetura. Além das atividades profissionais, é acadêmico do curso de Engenharia Civil pela UFCG - CCTA - campus Pombal-PB,

${ }^{4}$ Possui graduação em Arquitetura e Urbanismo pela Universidade Federal da Paraíba (UFPB 2016), especialização em Gestão de Políticas do Patrimônio Cultural pela Faculdade Maurício de Nassau (2018) e mestrado em Desenvolvimento Urbano (MDU) pelo Departamento de Arquitetura e Urbanismo da Universidade Federal de Pernambuco (UFPE - 2019), canalizando seus estudos para o projeto paisagístico e o bem-estar. Exerce o cargo de arquiteto como técnica na Prefeitura Municipal de Marí/ PB desde 2016, atuando na elaboração de projetos arquitetônicos e urbanos. É docente na Faculdade Santa Maria (FSM) desde 2018.

${ }^{5}$ Possui graduação em Arquitetura e Urbanismo pela Universidade Federal da Paraíba (2014) e mestrado em Energias Renováveis pela Universidade Federal da Paraíba (2017) na linha de pesquisa em Meio Ambiente, Economia e Aproveitamento Energético. Atualmente é professor da Faculdade Santa Maria (FSM) em Cajazeiras e das Faculdades Integradas de Patos (FIP). Tem experiência na área de Arquitetura e Urbanismo e Sustentabilidade, com ênfase em Projeto de Arquitetura e Urbanismo.

${ }^{6}$ Arquiteta e Urbanista, graduada pela Universidade Federal da Paraíba (UFPB) (2013) e mestre pelo Programa de Pós-graduação em Arquitetura e Urbanismo da Universidade Federal da Paraíba
} 
RESUMO: $O$ presente trabalho descreve 0 desenvolvimento da habitação de interesse social no Brasil, analisa as diretrizes de conforto térmico em clima quente e seco, para que possa ser desenvolvido um anteprojeto de habitação de interesse social que consiga atender as necessidades e perfil dos moradores, e que apresente estratégias de conforto térmico na tipologia. Sobre o desenvolvimento da habitação de interesse social no Brasil, é importante destacar que a oferta de trabalho foi um fator responsável pelo acúmulo populacional nos centros urbanos do país. Esse acúmulo gerou o déficit por moradia, contribuindo para a atual configuração das cidades brasileiras. Como forma de minimizar esse problema social, desde a década de 30 - que remete aos primeiros exemplos de conjuntos habitacionais - que políticas públicas são implantadas na tentativa de enfrentar esse déficit habitacional. Atualmente, o maior exemplo de programa social é o Minha Casa Minha Vida, criado no ano de 2009. Percebe-se que as políticas habitacionais implantadas apenas mascaram o problema, produzindo construções que pouco, ou nada, apresentam soluções para o conforto ou qualidade de vida dos seus moradores. A necessidade de adaptação às condições adversas impostas pelo clima e aos recursos disponíveis na região é o ponto de partida para o desenvolvimento de estratégias de aproveitamento das condicionantes locais para a elaboração de uma arquitetura responsiva ao conforto térmico dos seus usuários, buscando soluções através das diretrizes estabelecidas pela NBR 15220 - Desempenho Térmico de Edificações (ABNT, 2005) para a zona bioclimática 7.

PALAVRAS CHAVE: Habitação Social; Adequação Climática; Zona Bioclimática 7; Conforto Térmico.

ABSTRACT: This paper describes the development of housing of social interest in Brazil, analyzes the guidelines of thermal comfort in hot and dry weather, for the development of a social housing project that can meet the needs and profile of the residents and that presents thermal comfort strategies in its typology. Regarding the development of housing of social interest in Brazil, it is important to emphasize that the labor supply was a factor responsible for the accumulation of population in the urban centers of the country. This accumulation generated the housing deficit, contributing to the current configuration of Brazilian cities. As a way to minimize this social problem, since the 1930s - which refer to the first examples of housing developments - public policies have been implemented in an attempt to address this housing deficit. Currently, the greatest example of a social program is Minha Casa Minha Vida, created in 2009. The housing policies implemented only mask the problem, producing constructions that show little or no solution to the comfort or quality of life of their residents. The need to adapt to the adverse conditions imposed by the climate and the available resources in the region is the starting point for the

(PPGAU-UFPB) (2015). Atualmente é professora do curso de Bacharelado em Arquitetura e Urbanismo da Faculdade Santa Maria - Cajazeiras-PB. Tem experiência ministrando aulas e trabalhando com iniciação científica nos seguintes temas: acessibilidade, mobilidade, avaliação pósocupação, sistema de espaços livres, avaliação pós-ocupação e representação e concepção de projeto. 
development of strategies to take advantage of the local conditions for the elaboration of an architecture responsive to the thermal comfort of its users, seeking solutions through the guidelines established by NBR 15220 - Thermal Performance of Buildings (ABNT, 2005) for the bioclimatic zone 7.

KEYWORDS: Social Housing; Climate Adequacy; Bioclimatic Zone 7; Thermal comfort. 


\section{INTRODUÇÃO}

A Constituição Federal do Brasil de 1988 ressalva que todo cidadão tem direito à moradia (BRASIL,1988). O avanço desordenado das cidades devido ao acúmulo populacional acarretou no déficit habitacional, contribuindo com construções sem condições de habitabilidade, levando à necessidade de as políticas públicas suprirem esse problema da moradia popular.

O desenvolvimento da habitação social no Brasil veio como forma de minimizar esse déficit e ofertar o direito da casa própria, mas vem sendo muito criticado devido às condições propostas aos moradores. Segundo Benetti (2012), se os recursos investidos na habitação fossem bem empregados, teríamos construções de qualidade ofertadas aos residentes.

$\mathrm{Na}$ arquitetura, projetar não é só considerar o modelo e a quantidade de projetos que determinada área suporta para ser executado; vai além disso: é preciso analisar o local onde será inserida a edificação, e quais impactos pode gerar sobre o meio ambiente para recorrer a buscas por estratégias eficientes a fim de dirimi-los ou, ao menos, amenizá-los. Um projeto tem que servir aos seus usuários de forma segura, garantindo conforto em seu interior independente de como se comportam as condições climáticas externas, e, principalmente, suprir todas as suas necessidades, permitindo o uso de forma adequada.

Segundo Edwards (2008, p. 03), "a civilização contemporânea depende de edificações para seu resguardo e sua existência, mas nosso planeta não é capaz de continuar suprindo a atual demanda de recurso." Para ele, esse tipo de situação precisa ser levado a sério, já que a construção civil consome $50 \%$ dos recursos do planeta. $\mathrm{O}$ autor complementa ainda que grande parte do consumo energético de uma edificação está em garantir o conforto ao usuário como forma de aquecer, iluminar e ventilar, sendo que somente $3 \%$ são gastos na construção.

Considerando a abrangência do tema, o foco principal desse trabalho é o desenvolvimento de uma nova concepção de anteprojeto de habitação de interesse 
social para a cidade de Triunfo-PB, com aplicação de estratégias de adequação climática para a área delimitada.

No conjunto habitacional de Triunfo-PB, residem 39 famílias, vivendo em condições precárias sem infraestrutura necessária para as condições de moradia, além de estarem situadas de forma segregada da cidade.

Em meio ao emprego equivocado de materiais e artifícios amplamente difundidos como propícios ao clima local, a Associação Brasileira de Normas Técnicas (ABNT) estabeleceu, como um compêndio voltado à aplicação satisfatória das estratégias de desempenho térmico, a NBR 15220-3: Desempenho térmico de edificações (ABNT, 2005), com parâmetros e condições de conforto da edificação específicos a cada zona bioclimática brasileira.

A falta de qualidade nas habitações de interesse social construídas no Brasil pode ser atribuída ao fato de as políticas atuais focarem em fornecer somente 0 objeto "casa", sem a mínima preocupação na necessidade e conforto para os moradores. Mudar a forma como os projetos habitacionais de interesse social são desenvolvidos é uma necessidade real, e que merece a devida atenção, de modo a garantir construções salubres que, além de um valor estético, baseiem-se na necessidade da população de baixa renda, considerando a análise das condições climáticas como fator determinante para atingir o conforto da construção de modo a contribuir para a melhor qualidade de vida dos moradores.

\section{METODOLOGIA}

As classificações da pesquisa correspondem à abordagem qualitativa de caráter exploratório e de natureza aplicada.

O método inicial deu-se através da pesquisa bibliográfica, na qual são abordadas temáticas ligadas ao conforto e clima e habitação de interesse social. A pesquisa foi fundamentada em princípios da Lei Federal $n^{\circ} 11.124$ de 16 de junho de 2005 e na NBR 15.220 (ABNT, 2005). 
As etapas metodológicas deram-se através das diretrizes projetuais para o desenvolvimento de um anteprojeto de habitação de interesse social, sendo divididas em análise do terreno e projeto.

A primeira etapa da análise foi a identificação e levantamento da área de implantação e entorno através de visita in loco, fazendo uma análise visual e fotográfica, e itens como levantamento topográfico, já que a cidade não dispõe nessa área de estudo, e uso e ocupação do solo.

Em seguida, a verificação e adequação climática local, sendo indispensável a coleta de dados climáticos no desenvolvimento da pesquisa sobre as características gerais do clima quente e seco. A consulta aos dados específicos da região em que se localiza o objeto de estudo considerou a estação meteorológica de São Gonçalo-PB e foi viabilizada através do endereço eletrônico do INMET.

Foram investigados os dados anuais referentes aos últimos dez anos em relação às temperaturas máximas e mínimas, direção dos ventos e umidade relativa do ar, sendo apresentado no levantamento de dados através de uma média obtido a cada ano, para que possa ser feito um comparativo entre ambos e perceber as mudanças ocorridas.

Como auxílio aos estudos da insolação incidente nas fachadas e setores internos, de forma a ajudar nas estratégias de sombreamento e na melhor implantação da edificação, o software SketchUP foi utilizado como ferramenta para elaboração da volumetria e simulação exata a partir da geolocalização (CAVASSANI, 2015, p. 13) da cidade de Triunfo-PB, com a inserção das suas coordenadas geográficas $\left(06^{\circ} 34^{\prime} 44^{\prime \prime} \mathrm{S} 38^{\circ} 35^{\prime} 49^{\prime \prime} \mathrm{W}\right)$.

As estratégias foram analisadas voltadas ao clima quente e seco, complementando-se com diretrizes apresentadas na NBR 15.220 (ABNT, 2005) para a Zona Bioclimática 7.

$\mathrm{Na}$ etapa inicial, fez-se necessária a verificação do código de obra e parcelamento urbano da cidade de Triunfo-PB juntamente com as diretrizes do PMCMV, para auxiliar na elaboração da concepção e buscar soluções adequadas à área de implantação.

Apresentar projetos correlatos de habitação de interesse social com soluções projetuais caracterizada por traços distintos e que estejam implantados em regiões 
com climas diferentes para que se possam avaliar as estratégias de conforto, bem como buscar materiais que contribuam para a minimização dos efeitos do clima quente e seco, para que possa ajudar na qualidade e conforto da edificação, foi uma das etapas importantes do projeto.

Em seguida, foi montado um fluxograma e uma setorização, para facilitar na ligação das áreas de forma a buscar uma melhor implantação dos ambientes. Foi criada uma maquete conceitual para servir como ferramenta facilitadora do processo criativo, na materialização de um conceito e na visualização das relações espaciais com o entorno.

Essas informações serviram de base para o desenvolvimento do anteprojeto, sendo apresentados através de desenhos técnicos: plantas, cortes, fachadas, perspectivas, e um memorial descritivo para que se possam obter as informações necessárias.

Dois projetos foram escolhidos para embasar o anteprojeto desenvolvido e apresentado no final deste trabalho. O critério de escolha deu-se através de referências que apresentam soluções para o conforto térmico em habitações de interesse social, além de uma clara demonstração com a qualidade projetual.

Desenvolvido pelo escritório 24.7 Arquitetura Design no ano de 2010, o projeto foi vencedor do $1^{\circ}$ prêmio no Concurso Público Nacional de Arquitetura para Novas Tipologias de Habitação de Interesse Social Sustentáveis. A proposta (Figura 01) propõe tipologias de casas térreas possibilitando os usuários utilizarem de acordo suas necessidades (DELAQUA, 2013).

Figura 01. Condomínio de Casa, Campinas-SP.
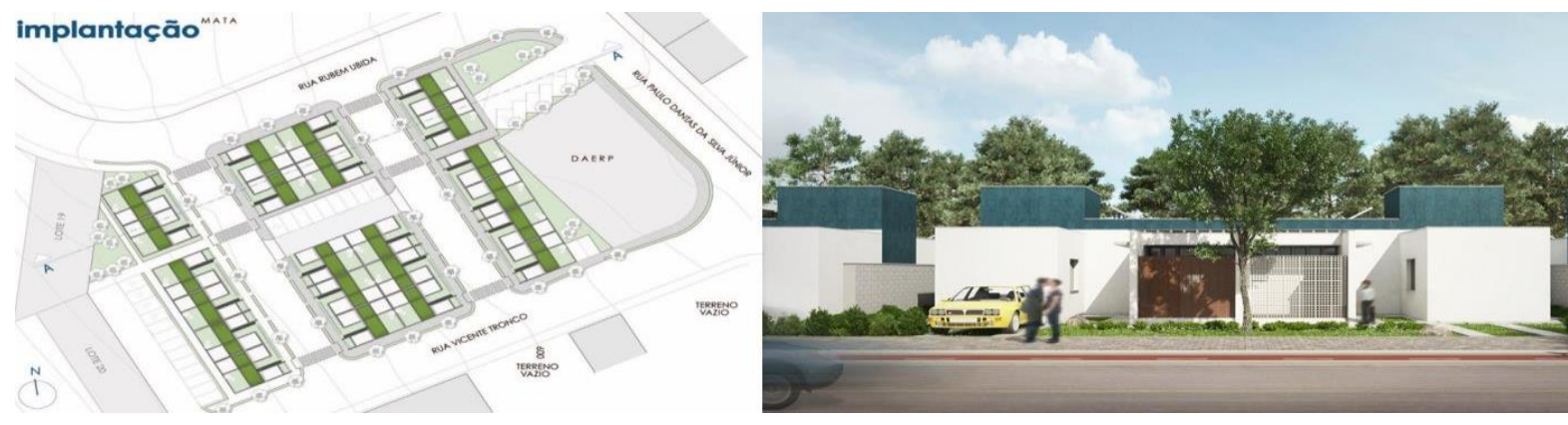
Disponível em: <https://www.archdaily.com.br/br/01-141035/habitacao-de-interessesocial-sustentavel-slash-24- dot-7-arquitetura-design>. Acesso em: 29 mar. 2019.

Para os arquitetos, o objetivo era produzir uma concepção que transmitisse sensações positivas juntamente a um projeto bioclimático, além de produzir uma casa compacta que pudesse atender as necessidades dos usuários sem deixar de lado a qualidade projetual. A concepção foi desenvolvida a partir de dois blocos lineares que estão ligados entre eles por um terceiro bloco. O programa de necessidade é formado de dois quartos, um banheiro, sala de estar, jantar, cozinha e área de serviços, possibilitando a expansão para um terceiro quarto, em caso de crescimento familiar. A proposta foi desenvolvida de forma acessível para que atenda às necessidades de qualquer usuário (DELAQUA, 2013).

Os arquitetos buscaram soluções de resfriamento através de elementos vazados e esquadrias em pontos estratégicos, permitindo uma ventilação cruzada e iluminação natural. Além dessas estratégias, a cobertura foi mesclada entre telhas termoacústicas e cobertura ajardinada de forma a contribuir para o conforto ambiental (DELAQUA, 2013).

A proposta foi desenvolvida para um concurso de habitação social Construye para Crecer no ano de 2017, pelos arquitetos Rafael Arana Parodi, Carlos Suasnabar Martínez, Amed Aguilar Chunga e Santiago Nieto Valladares, em um terreno de 3,7 hectares, localizado no bairro de Belém, na cidade de lquitos, Peru. $O$ projeto foi considerado o melhor na categoria profissional e recebeu menção honrosa na categoria eco-sustentável (BAYONA, 2018).

O objetivo do concurso foi ajudar no desenvolvimento urbano, além de abordar questões sustentáveis e de prevenção sobre desastres naturais. A proposta apresentada permite aos utilizadores a liberdade de expansão nas residências de forma que os moradores ampliem de acordo com suas necessidades ou condições, mas sem ultrapassar a base de apoio.

As habitações são formadas por um bloco central estrutural sendo complementado no seu entorno por estrutura de madeira fazendo o fechamento dos 
quartos. A proposta possibilita a criação de um pavimento superior permitindo uma casa unifamiliar ou multifamiliar como mostra a figura 02 (BAYONA, 2018).

Figura 02. Propostas Planta Baixa.

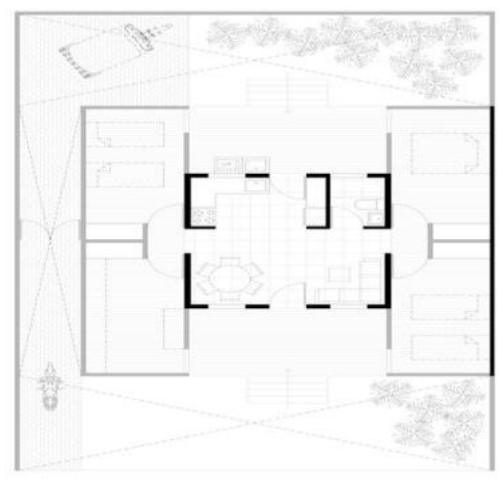

UNIFAMILIAR 1 PISO

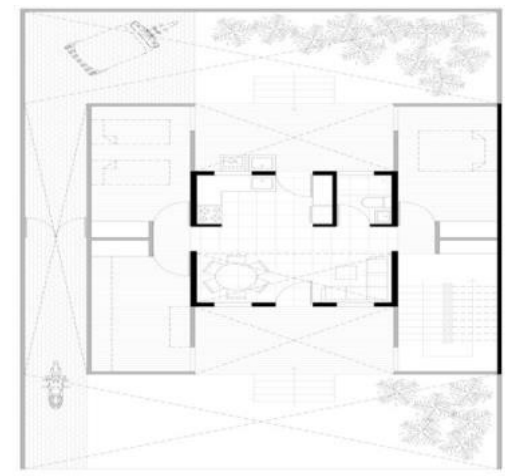

UNIFAMILIAR 2 PISOS (1ER NIVEL)

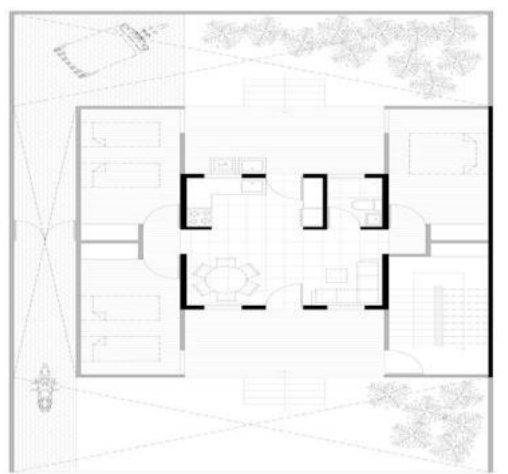

MULTIFAMILIAR 2 PISOS (1ER NIVEL)

Disponível em: <https://www.archdaily.com.br/br/888895/arquitetos-propoem-120habitacoes-sociais- incrementais-e-flexiveis-para-iquitos-peru>. Acesso em: 29 mar. 2019.

De modo a garantir o conforto térmico nas edificações, considerando o excesso de incidência solar e de precipitações na região, os arquitetos optaram por suspender as edificações do solo e criar um telhado que permitisse a passagem de ar como forma de resfriamento (BAYONA, 2018).

Os dois casos de estudo analisados apresentam propostas para uma habitação social que garantem uma arquitetura de qualidade com critérios que asseguram o conforto e que atendem às necessidades dos seus moradores. Para o anteprojeto apresentado no final desse trabalho, os critérios adotados para seu desenvolvimento assemelham-se com os casos analisados, onde se propõe uma concepção de habitação social com soluções de conforto térmico, implantação e qualidade projetual. Além desses critérios, as concepções apresentam um distanciamento do conceito comum de uma proposta onde os projetos de habitação social não apresentam qualidade arquitetônica. As tipologias apresentadas expõem um resultado estético, contribuindo para uma melhor qualidade vida de seus moradores através de habitações integradas. 
A escolha do local é uma forma de propor uma nova concepção de habitação social comparando com a situação atual. A cidade de Triunfo-PB, pertencente ao sertão paraibano, fica localizada a $590 \mathrm{~km}$ da capital, com uma população estimada em 9.466 habitantes, e sua economia constitui-se basicamente em agricultura e pecuária (IBGE, 2016).

A área de estudo fica localizada na zona oeste, de forma segregada da cidade. O local apresenta condições precárias aos moradores devido à proximidade com matadouro público e a não desfrutar de um saneamento básico.

Como citado anteriormente, residem 39 famílias no conjunto habitacional. No desenvolvimento do anteprojeto, busca-se fazer o remembramento entre duas quadras como forma de oferecer melhores condições de habitabilidade, através de espaços de vivências e buscas por soluções de conforto aos moradores. Foi desenvolvido o levantamento topográfico da área escolhida, sendo utilizado o terreno pertencente à prefeitura de Triunfo-PB e a área onde está implantada boa parte das habitações. A escolha da área deu-se como crítica sobre o que foi construído e imposto às famílias carentes que foram "beneficiadas".

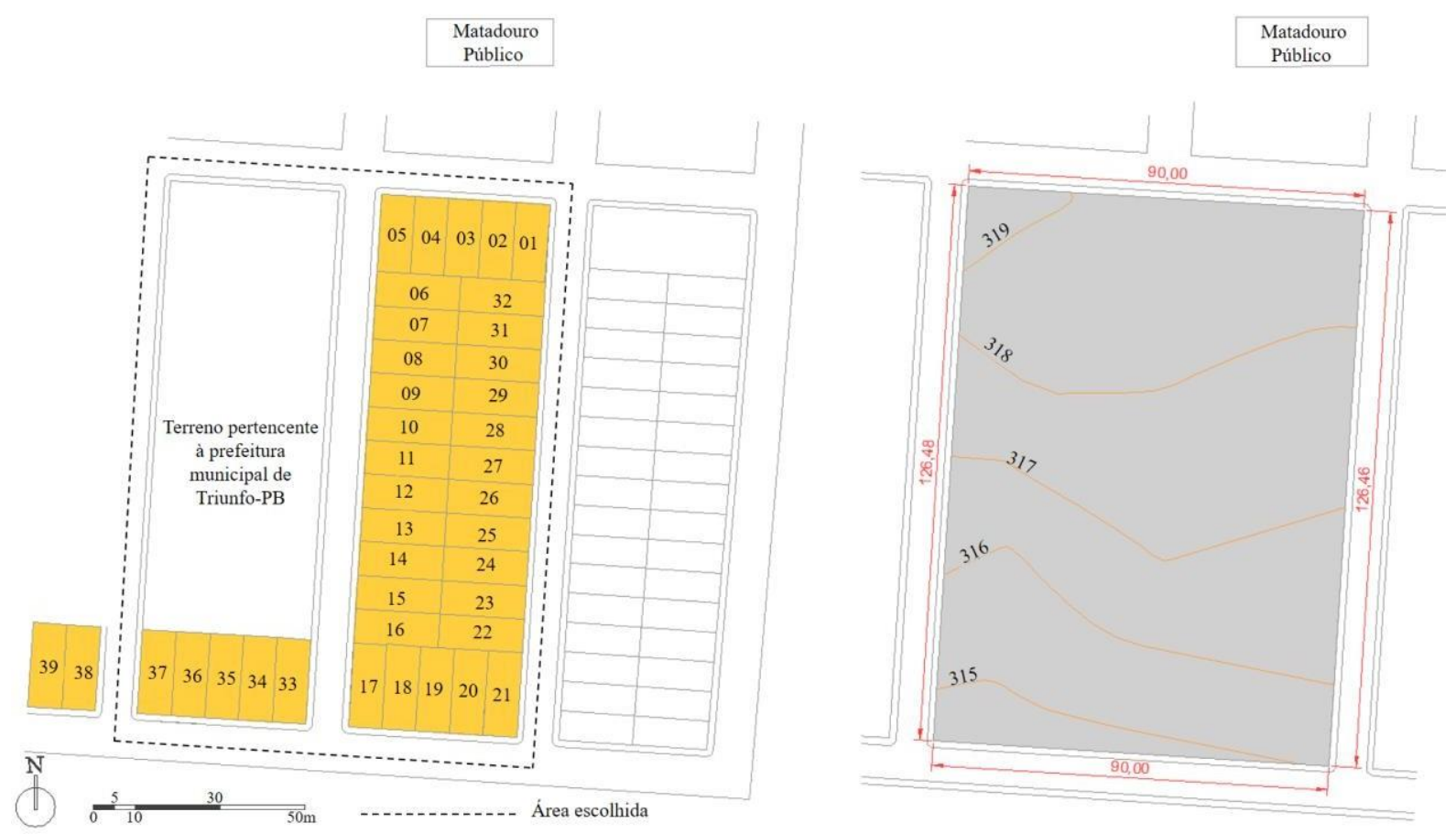

Mapa 01. Área de Estudo.

Fonte: Elaborado pelo autor, 2019. 
Em seguida buscou-se informações sobre a orientação solar como estratégias de melhor implantação. "A carta solar torna-se, assim, uma ferramenta de auxílio ao projeto bastante útil, pois diz a posição exata do sol num determinado momento, [...] (Lamberts, Dutra e Pereira, 2012, p.119).

De acordo com IBGE (2016), a cidade de Triunfo-PB fica situada sobre a latitude $6^{\circ} 34^{\prime} 44^{\prime \prime}$ S. A partir dessa informação, buscou-se fazer um estudo sobre carta solar.

Através do INMET (2019), foi elaborado um levantamento em médias anuais referentes aos últimos 10 anos, como mostra o esquema 03, para que, através desses dados, possam ser visualizados os períodos mais quentes e mais frios do ano, a umidade relativa do ar, e a direção dos ventos. Através desses dados, buscam-se estratégias no desenvolvimento do anteprojeto para que a edificação consiga transmitir conforto térmico aos moradores.

O primeiro passo foi desenvolver um fluxograma e setorização para facilitar na distribuição dos ambientes, existindo um processo evolutivo como busca de atingir as necessidades e manter uma habitação funcional. Após três estudos, iniciou-se o desenvolvimento da concepção, cuja ideia era conceber uma habitação que permita ser implantada a qualquer orientação solar e que possa ser modificada internamente sem interferir nas fachadas.

Diante dessa etapa, iniciou-se um estudo de volumetrias através de uma maquete conceitual, produzida através de bloquinho de Medium Density Fiberboard (MDF) para possibilitar uma noção prévia, surgida a partir do estudo de setorização, assim facilitando no desenvolvimento de formas e volumes. 
Figura 3. Simulação de Insolação nas fachadas.
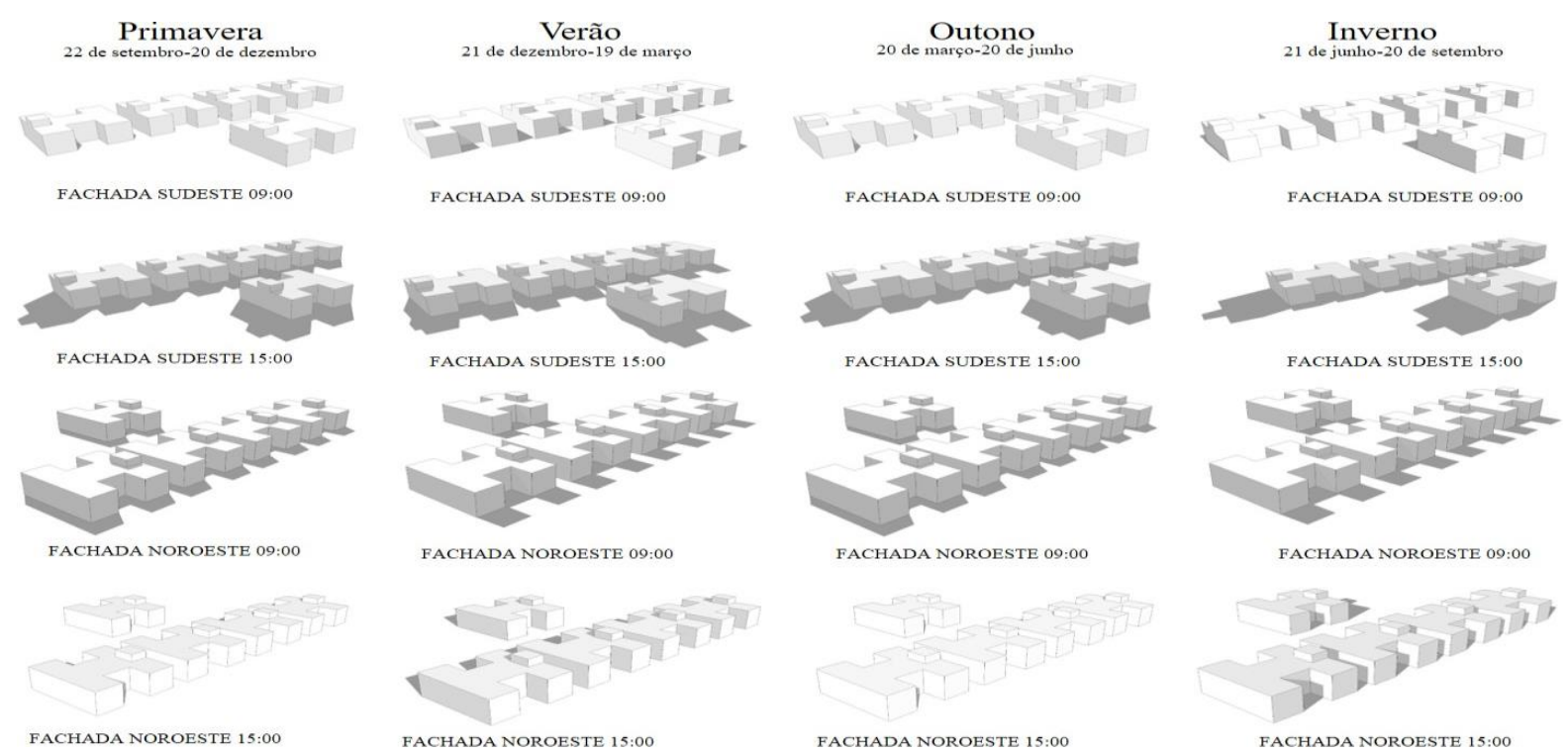

Fonte: Elaborado pelo autor, 2019.

Logo após, com auxílio do software de computador SketchUP, foi desenvolvido um protótipo (Figura 13), que serviu de base para o estudo de insolação nas fachadas, como uma forma de prever a melhor implantação. Foi analisado a partir do primeiro dia de cada estação, no horário de 09h e às $15 \mathrm{~h}$, assim, percebe-se que a fachada sudeste está exposta ao sol quase o ano inteiro pela manhã e a fachada noroeste, por completa pela tarde. A partir dessa simulação, buscam-se elementos construtivos e arborização como forma de amenizar essas áreas "afetadas".

A proposta do anteprojeto de arquitetura será elaborada de acordo com o código de obras e parcelas urbanas da cidade de Triunfo-PB, juntamente com a Cartilha Minha Casa Minha Vida, a NBR 9050 de acessibilidade e NBR 15.220 de desempenho térmico de edificação.

A princípio, a proposta do anteprojeto seria desenvolvida de acordo com as informações recomendadas pela cartilha de habitação de interesse social, tendo como área de $35,00 \mathrm{~m}^{2}$ a unidade, mas, devido a essa metragem estabelecida dificultar um planejamento de uma habitação que atendesse as necessidades de todos, principalmente de uma pessoa com deficiência $(P c D)$, optou-se elaborar um 
anteprojeto seguindo a legislação da cidade de Triunfo-PB; Dessa forma, viabilizava um desenvolvimento de anteprojeto capaz de suprir as informações estabelecidas pela NBR 9050/2015, além de outro fator importante a ser considerado, que acessibilidade é lei.

De acordo com Triunfo (2006), qualquer edificação construída no perímetro urbano deve seguir o alinhamento e recuo obrigatórios, sendo no mínimo 4,00 m de afastamento frontal, $1,50 \mathrm{~m}$ de afastamento lateral e 2,00 $\mathrm{m}$ de afastamento de fundo, os lotes devem ser a partir de 10,00 m de frente, com área mínima de 200,00 $\mathrm{m}^{2}$. As vagas de estacionamento público devem ser com 3,00 m de largura, com área mínima por vaga de $15,00 \mathrm{~m}^{2}$.

As edificações para fins residenciais devem seguir as condições exigidas pelo código de obras e posturas urbanas quanto às dimensões mínimas para sua aprovação: pé direto de 2,60 de altura, sala com largura de 2,50m com área de $8,00 \mathrm{~m}^{2}$, cozinha com largura 2,00 com área de $7,00 \mathrm{~m}^{2}$, quarto com largura de $2,50 \mathrm{~m}$ com área $8,40 \mathrm{~m}^{2}$ podendo ser admitido um segundo quarto com um área inferior e banheiro com largura de 1,20m com área de 2,50m² (TRIUNFO, 2006).

\section{RESULTADOS E DISCUSSÃO}

O anteprojeto apresentado no final desse trabalho será desenvolvido seguindo o programa de necessidades apresentado pela cartilha, mas buscando trabalhar de forma que consiga ofertar uma arquitetura de qualidade. De acordo com o código de ética do Conselho de Arquitetura e Urbanismo (CAU), "o arquiteto e urbanista deve considerar a profissão com uma contribuição para o desenvolvimento da sociedade" (BRASIL, 2013, p.09).

O anteprojeto de habitação de interesse social traz como concepção uma proposta que assume a função de proporcionar uma melhor qualidade de vida aos moradores, atender as suas necessidades e garantir conforto térmico, além de ofertar espaços de vivências e áreas verdes como forma de inter-relacionar o convívio social. O terreno está localizado na cidade de Triunfo-PB, com área de 
$11.383,26 \mathrm{~m}^{2}$, e o projeto circunda uma área de $52,75 \mathrm{~m}^{2}$. A proposta consiste em um único pavimento, formado a partir da união entre três blocos (Figura 4), sendo composto pelos seguintes ambientes: sala, cozinha/espaço de serviço, dois quartos e um banheiro.

Figura 4. Proposta de habitação.
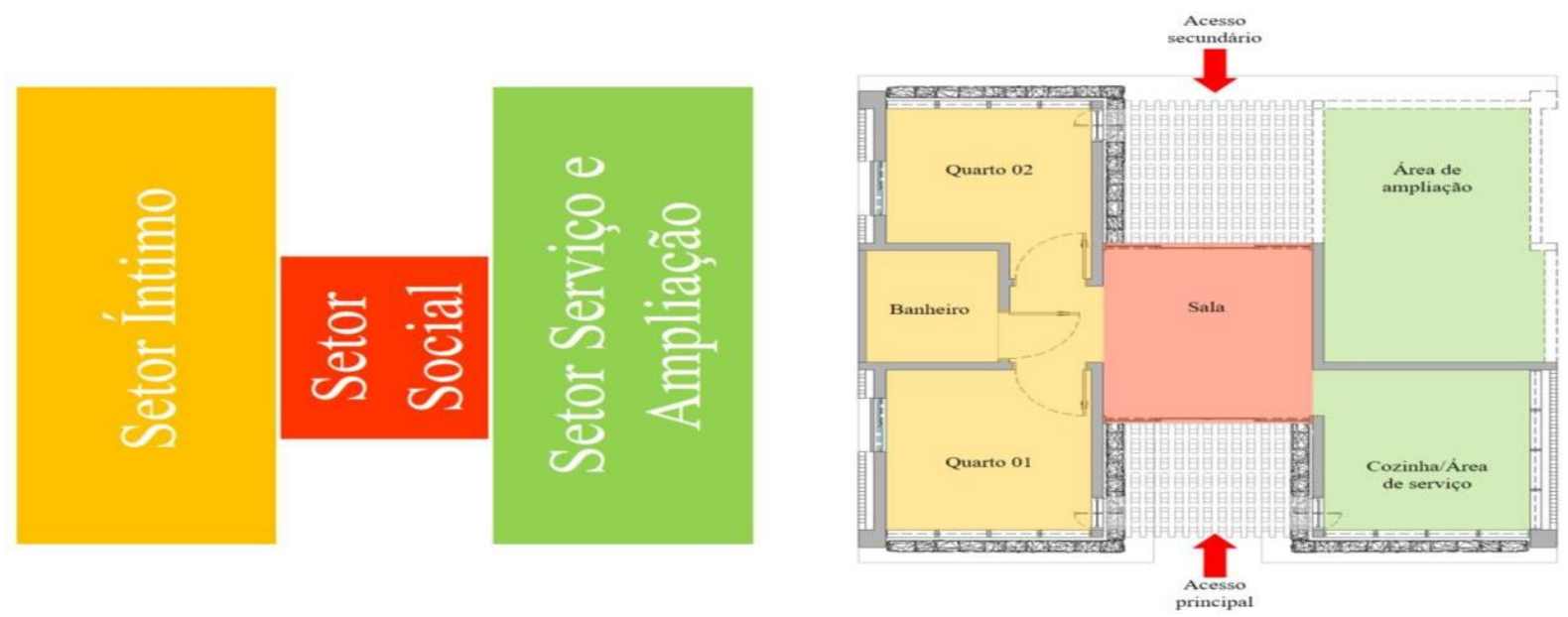

Fonte: Elaborado pelo autor, 2019.

O anteprojeto tem como conceito proporcionar uma tipologia que permita ser alterada de acordo com as necessidades dos moradores e que possibilite uma dinâmica de mudança entre os ambientes. Proporcionar um elo entre homem e natureza buscando identidade local e sensação de pertencimento ao lugar através do uso dos materiais.

O partido arquitetônico surge das figuras geométricas, em específico do cubo. Através da forma, foram moldadas ideias até chegar à concepção final.

Os estudos feitos para concepção e implantação do projeto deram-se através de importantes fatores e requisitos a considerar. Foram pensados de acordo com as normas e exigências locais, o uso e ocupação do solo, características do terreno e condicionantes climáticos.

Diante dessas informações, foram desenvolvidas várias propostas, como forma de amadurecimento da ideia e busca pela melhor solução.

A implantação das habitações no terreno necessariamente atende a requisitos legais, em geral estabelecidos por códigos de obras e posturas urbanas da cidade. 
Para o posicionamento, levaram-se em conta aspectos tais como: movimento do sol e direção dos ventos, e a distribuição deu-se através de um ângulo de $90^{\circ}$ referente à rua. A ideia foi propor a implantação de 50 casas no terreno (Figura 16) criando entre elas espaços de convívio e sociabilidade.

A primeira habitação está inserida a uma distância de $10,30 \mathrm{~m}$ da rua, as calçadas frontais e dos fundos possuem largura de $1,50 \mathrm{~m}$ e $2,00 \mathrm{~m}$ nas laterais, permitindo uma melhor circulação entre as unidades. $\mathrm{O}$ arruamento planejou-se trabalhar com uma área livre de 4,00m de largura para que possa agregar espaços para o cultivo de hortas, plantas medicinais e frutíferas, além de espaços de convivência. A taxa de ocupação deu-se em $23,75 \%$ com o índice de aproveitamento em 0,23.

Figura 5. Espaços coletivos.

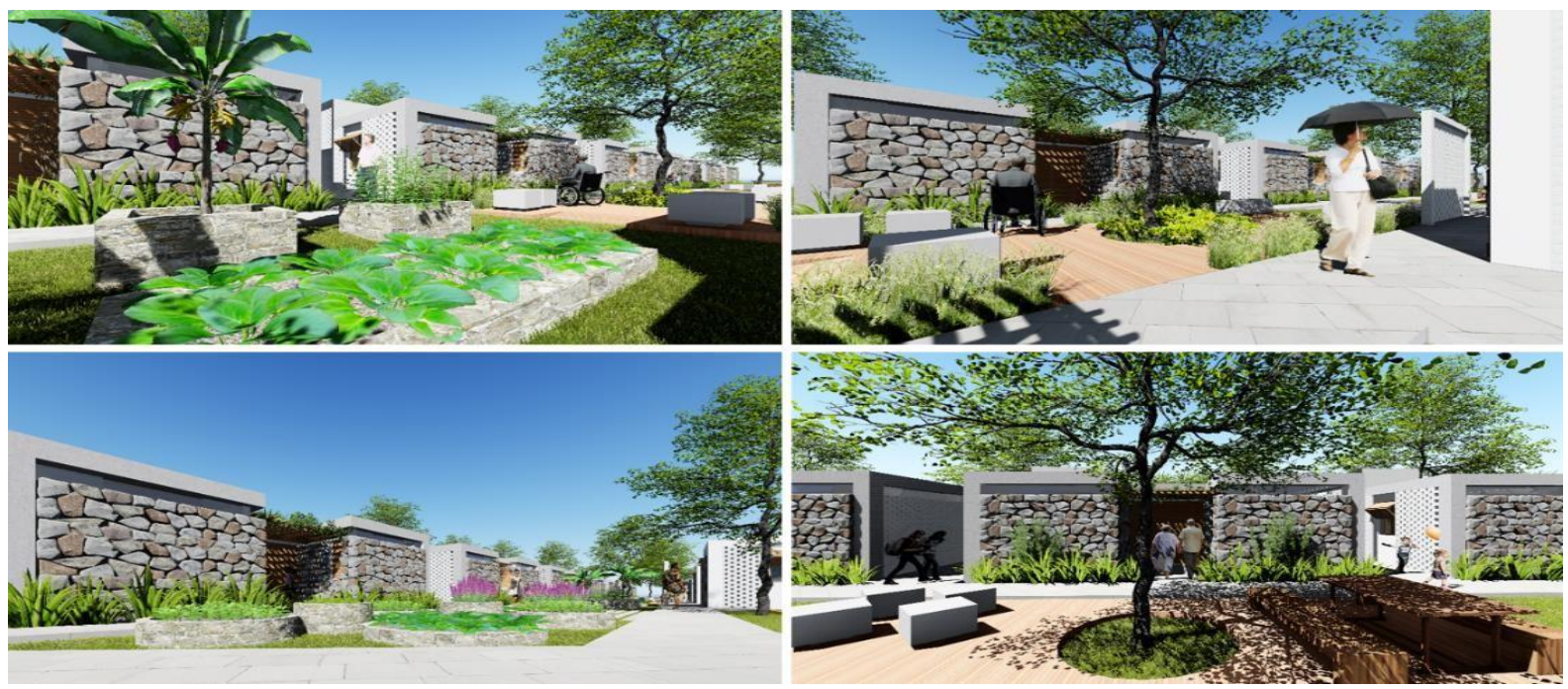

Fonte: Elaborado pelo autor, 2019.

A proposta habitacional foi desenvolvida na busca de apresentar condições apropriadas para uma moradia levando sempre em consideração os usuários, de forma a contribuir para o desenvolvimento das famílias que residem em conjuntos habitacionais, que, por muitas vezes, são expostas a moradias sem condições de habitabilidade.

A unidade foi desenvolvida de forma acessível, para que atenda ao perfil de qualquer morador, permitindo sua autonomia sobre o espaço. A concepção tem 
comprometimento com a inclusão de pessoas com deficiência de forma a conceder uma habitação digna.

Figura 6. Proposta Final.

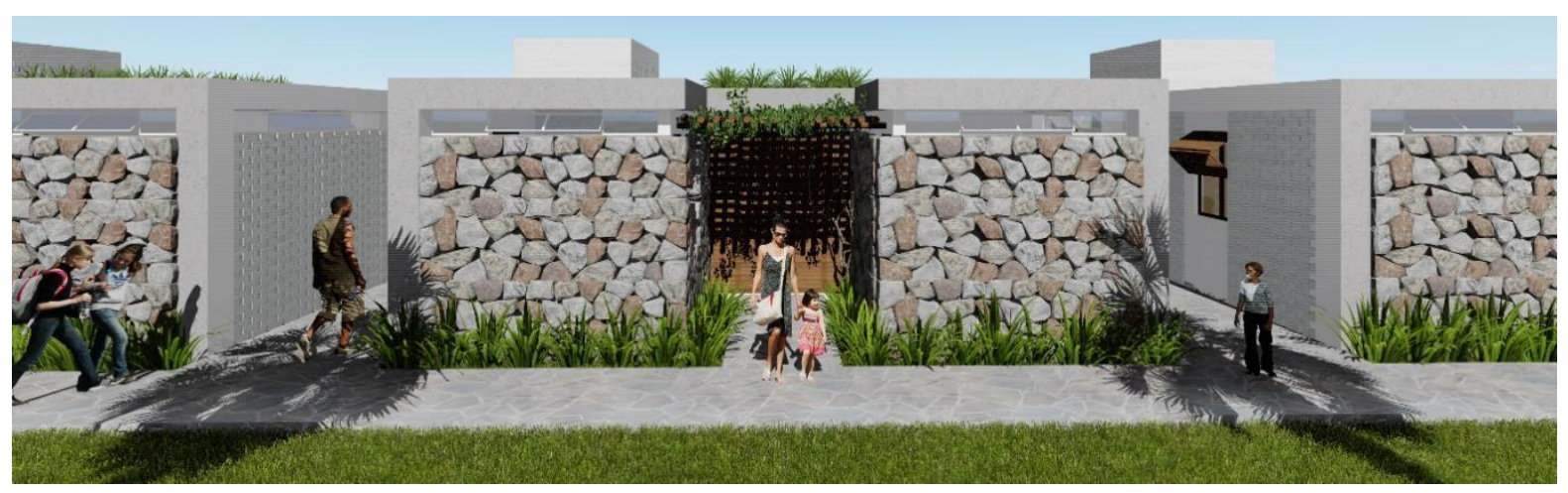

Fonte: Elaborado pelo autor, 2019.

A distribuição das aberturas foi pensada de forma que permita uma ventilação cruzada entre os ambientes, gerando espaços mais agradáveis além de possibilitar a passagem de ar para as habitações vizinhas.

A estrutura será composta por pilares e vigas em concreto, dimensionados em conformidade com o projeto arquitetônico. A laje será do tipo pré-moldada; na área da sala, a laje será impermeabilizada devido à inserção do telhado verde.

As paredes serão de alvenaria de tijolos cerâmicos de oito furos nas

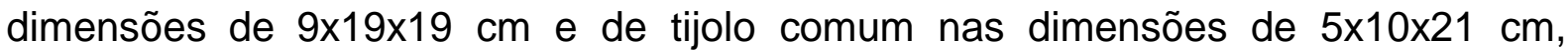
assentado com argamassa de cimento, areia média e água, as alvenarias receberão as três camadas de acabamento- chapisco, emboço e reboco, exceto a parte externa do bloco da caixa de água, que ficará no tijolo comum aparente sobre uma camada de tinta na cor branco gelo. As demais receberão acabamento em massa acrílica e serão pintadas na cor branco neve.

Para os elementos de proteção, foram utilizados o tijolo comum e rochas magmáticas intrusivas como camada protetora da edificação. $O$ assentamento será feito de forma a manter um espaço de ar impossibilitando a incidência solar direta, mas permitindo a passagem do ar. O tijolo comum será assentado de forma vazada criando uma espécie de cobogó (Figura 7). 
Figura 7. Estratégias de conforto.

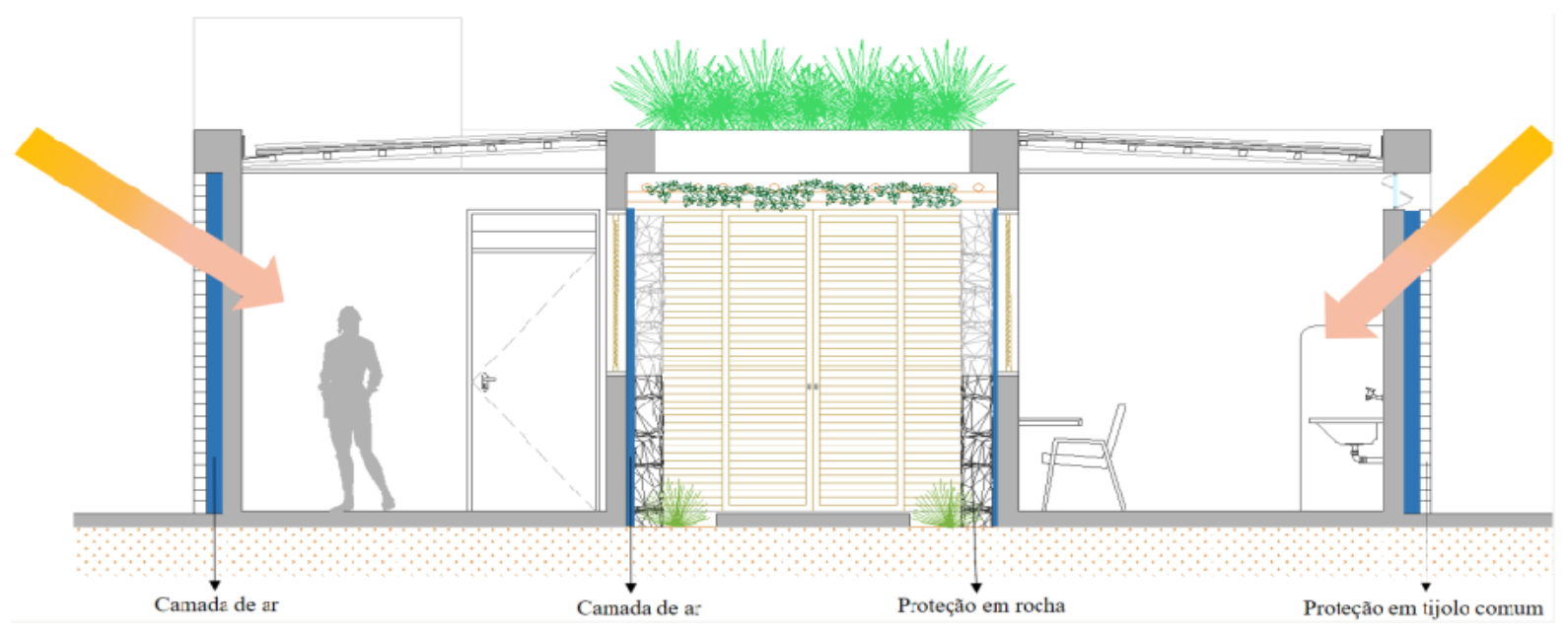

Fonte: Elaborado pelo autor, 2019.

Essa camada protetora age como atraso térmico na edificação, possibilitando aos moradores um conforto ambiental por mais tempo sobre os ambientes.

A estrutura da cobertura será em três tipos: no setor íntimo e serviço, será executada em telha sanduíche com poliuretano (telhas termoacústicas), com inclinação de 5\%. Esse material será utilizado para aumentar o isolamento térmico e a acústica do local, minimizar os gastos com energia e principalmente promover espaços mais agradáveis.

Já no setor social, a cobertura será em telhado verde, tendo como espécie a Aloe Vera (Babosa) por ser uma planta típica do bioma caatinga, visto que a proposta da habitação fica no semiárido brasileiro, além de ser uma espécie que não necessita de um consumo diário de água.

A área de acesso à edificação terá sombreamento através de um caramanchão, executado com madeira de reflorestamento ou por espécie local em formato de cipó. A vegetação para sombrear a área será o jasmim da índia, um tipo de trepadeira que se adapta às condições locais.

As janelas $\mathrm{J} 1$, como especificado no quadro de esquadrias, serão em madeira e vidro de $10 \mathrm{~mm}$ com abertura em correr e com uma proteção de acionamento em camarão, criando uma espécie de marquise, impossibilitando a incidência solar sobre o vidro e servindo de proteção quando fechado. As janelas J2 serão todas em 
madeira com abertura pivotante e venezianas móveis, as J3 e J4 serão em vidro com alumínio branco e abertura maxi-ar.

Figura 8. Modelo esquadrias.

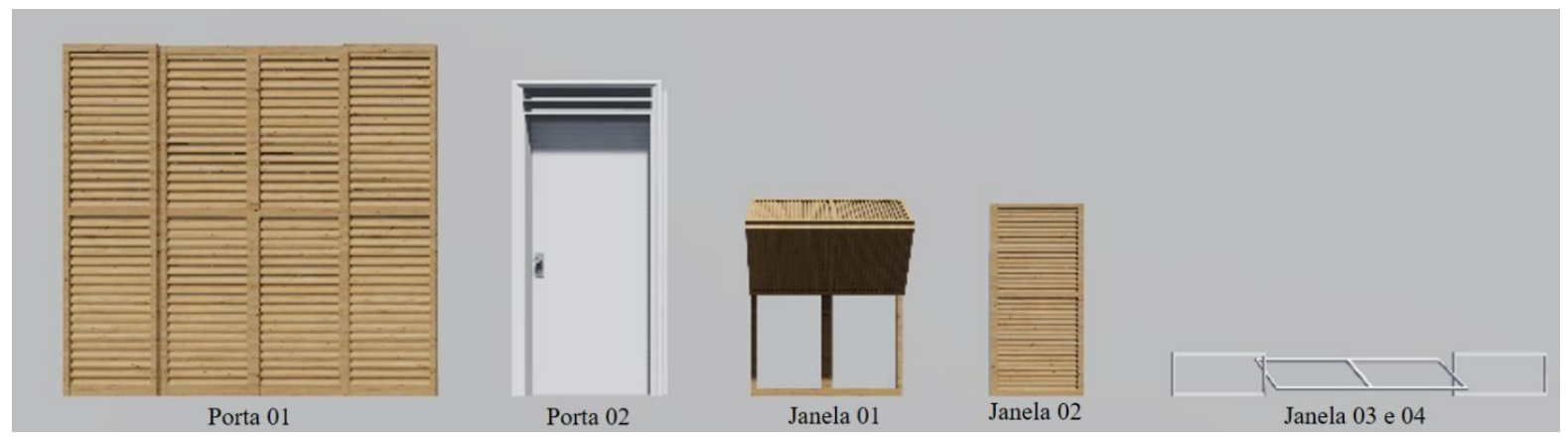

Para área interna, especificaram-se os seguintes materiais: o piso será todo em cimento queimado por ter uma aparência única e manter o ambiente natural, as paredes serão todas emassadas e pintadas com tinta acrílica fosca na cor branco neve, exceto as paredes do banheiro e a parede de trabalho da cozinha que serão revestidas com cerâmica no tamanho 10×10 na cor branca, forro em gesso em todos os ambientes, exceto na sala e banheiro que terão as lajes emassadas e pintadas na cor branco neve. Todas as tintas têm como referência a marca Coral.

A edificação possui um reservatório superior de $750 \mathrm{l}$ em polietileno com tampa da marca Tigre, além de dois reservatórios inferiores, sendo um para o consumo em períodos de secas com capacidade de 6.600 l e outro para manutenção do teto jardim, com capacidade de 8001 .

Buscou-se trabalhar com um paisagismo de forma simples, adequando a espécies quase todas locais sob a habitação, como forma de facilitar sua adaptação devido às altas temperaturas e à escassez hídrica, típicas do semiárido brasileiro. A proposta habitacional busca um equilíbrio entre cidade e natureza, já que as construções estão cada vez mais sem espaços verdes e áreas permeáveis, além de promover entre os moradores espaços comunitários para plantarem, por exemplo, o tomate, que poderá ser cultivado e consumido por todos que ali residirem, criando vínculos de convivência. 


\section{CONSIDERAÇÕES FINAIS}

Ao decorrer desse trabalho, é possível entender a evolução da habitação social no Brasil desde o período de Getúlio Vargas até o governo Lula com a criação do programa Minha Casa Minha Vida. Esse conhecimento foi essencial para o desenvolvimento deste trabalho, como forma de entender sobre o assunto, perceber o que leva a essa precarização em que as habitações de interesses sociais são desenvolvidas, onde muitas seguem padrões arquitetônicos e urbanísticos repetidos e que, na maioria das vezes, são implantados nas periferias das cidades. Vale salientar que o programa é válido, mas que deveria preocupar-se com o que está ofertando às famílias beneficiadas.

Considerando o tamanho territorial brasileiro e suas diversidades de clima, não deveria ser permitida uma repetição de projeto arquitetônico do governo, pois cada região apresenta características próprias e nem todas atendem as mesmas soluções adotadas.

As diretrizes postuladas pela NBR 15220 (ABNT, 2005) para o desempenho térmico das edificações constituem-se como instruções gerais para cada zona definida; cabe ao profissional interpretá-las e adequá-las com conveniência a cada situação. Vale ressaltar que essa é uma etapa inicial da pesquisa, a proposta precisa ser analisada, fazer alguns testes, medições como busca de um aperfeiçoamento e solução.

Dessa forma, apresentou-se uma proposta arquitetônica de uma habitação social para a Cidade de Triunfo-PB, como crítica sobre o que foi desenvolvido e imposto à sociedade. Pode-se concluir que a proposta apresentada cumpre seu objetivo ao propor uma tipologia que atenda às necessidades e aos padrões estabelecidos e que esteja adequada aos condicionantes climáticos locais. Foi desenvolvida a partir da união de três blocos de modo a possibilitar que os moradores utilizem de acordo com as suas necessidades e que possa ser implantada a qualquer situação do terreno sem que perca a sua estética. $O$ entorno apresenta espaços de convívio social e áreas verdes, não apenas como solução para favorecer 
o microclima, mas como forma de proporcionar espaços agradáveis e convidativos, de modo a valorizar a vida em conjunto, além de manter uma identidade através do uso dos materiais como forma de enaltecer o espaço, a cultura e as pessoas.

\section{REFERÊNCIAS BIBLIOGRÁFICAS}

ASSOCIAÇÃO BRASILEIRA DE NORMAS TÉCNICAS (ABNT). NBR 15220-3: Desempenho térmico de edificações - Parte 3: Zoneamento bioclimático brasileiro e diretrizes construtivas para habitações unifamiliares de interesse social. Rio de Janeiro, 2005. Disponível em: http://sinop.unemat.br/site_antigo/prof/foto_p_downloads/fot_9080nby_15220_pdf.pdf. Acesso em: 22 out. 2018.

ASSOCIAÇÃO BRASILEIRA DE NORMAS TÉCNICAS (ABNT). NBR 9050-2015: Acessibilidade a edificações, mobiliário, espaços e equipamentos urbanos - 3. ed. Rio de Janeiro, RJ, 11 out. 2015. Disponível em: <https://www.ufpb.br/cia/contents/manuais/abnt- nbr9050-edicao2015.pdf>. Acesso em: 03 abr. 2019.

BAYONA, Delia. Arquitetos propõem 120 habitações sociais incrementais e flexíveis para Iquitos, Peru. 2018. Disponível em: <https://www.archdaily.com.br/br/888895/arquitetospropoem-120-habitacoes-sociais- incrementais-e-flexiveis-para-iquitos-peru>. Acesso em: 29 mar. 2019.

BENETTI, Pablo. Habitação social e cidade: desafios para o ensino de projeto. Rio de Janeiro: Editora O Grupo Rio Ltda., 2012. 103 p.

BRASIL. Conselho de Arquitetura e Urbanismo. Resolução no 52, de 6 de setembro de 2013: Aprova o Código de Ética e Disciplina do Conselho de Arquitetura e Urbanismo do Brasil (CAU/BR). 179. ed. Brasília, DF, 16 set. 2013. Seção 1, p. 1-14. Disponível em: <https://transparencia.caubr.gov.br/arquivos/resolucao52.pdf>. Acesso em: 03 abr. 2019.

BRASIL. Constituição Federal Brasileira de 1988. Brasília-DF.

BRASIL. Constituição (2013). Resolução no 52, de 06 de setembro de 2013. Brasília-DF.

BRASIL. Lei no 11.124, de junho de 2005. Dispõe sobre o Sistema Nacional de Habitação de Interesse Social - SNHIS, cria o Fundo Nacional de Habitação de Interesse Social - FNHIS e institui o Conselho Gestor do FNHIS. Brasília, DF: Presidência da República, [2005]. Disponível em: http://www.planalto.gov.br/ccivil_03/_Ato2004-2006/2005/Lei/L11124.htm. Acesso em: 25 out. 2018.

DELAQUA, Victor. Habitação de Interesse Social Sustentável / 24.7 arquitetura design. 2013. Disponível em: <https://www.archdaily.com.br/br/01-141035/habitacao-de-interessesocial-sustentavel-slash-24-dot-7-arquitetura-design>. Acesso em: 29 mar. 2019.

EDWARDS, Brian. 0 guia básico para a sustentabilidade. Barcelona: Editorial Gustavo Gili, 2008. 226 p.

INSTITUTO BRASILEIRO DE GEOGRAFIA E ESTATÍSTICA (IBGE). Países. Brasil: Síntese. IBGE, 2016. Disponível em: https://paises.ibge.gov.br/\#/pt/pais/brasil/info/sintese. Acesso em: 18 out. 2018.

INSTITUTO NACIONAL DE METEOROLOGIA (INMET). Série Histórica - Dados Mensais da 


\section{Estação Convencional São Gonçalo/PB de 2008-2017. Banco de Dados Meteorológicos para Ensino e Pesquisa. Brasília: INMET, 2018. Disponível em: http://www.inmet.gov.br/projetos/rede/pesquisa/gera_serie_txt_mensal.php?\&mRelEstacao $=826$ 89\&btnProcesso=serie\&mRelDtInicio=01/01/2008\&mReIDtFim $=31 / 12 / 2017 \& m A$ tributos $=>$. Acesso em: 19 out. 2018.}

LAMBERTS, Roberto; DUTRA, Luciano; PEREIRA, Fernado O. R. Eficiência energética na arquitetura. 3. ed. São Paulo: $\mathrm{Pw}, 2012.366$ p.

Ministério das Cidades. Secretaria Nacional de Habitação. Cartilha Novas Regras do Programa Minha Casa Minha Vida. Brasília, DF: Secretaria Nacional de Habitação, [2017]. Disponível em: http://www.capacidades.gov.br/biblioteca/detalhar/id/348/titulo/- programa-minhacasa-minha-vida. Acesso em: 21 out. 2018.4

OLIVEIRA, Andréia Cardoso de. A influência das recomendações do zoneamento bioclimático brasileiro no desempenho térmico da envoltória de edificações de interesse social nos municípios da Paraíba. 2013. 234 f. Tese (Mestrado em Arquitetura e Urbanismo) Universidade Federal da Paraíba. João Pessoa, 2013.

ROMERO, Marta Adriana Bustos. Princípios Bioclimáticos para o Desenho Urbano. Brasília: Copymarket.com, $2000.266 \quad$ p. 2 Disponível <http://airesfernandes.weebly.com/uploads/5/1/6/5/5165255/princpios_bioclimticos_para_o_dese nho_urbano.pdf $>$. Acesso em: 05 abr. 2019.

RORIZ, Maurício. Uma proposta de revisão do zoneamento bioclimático brasileiro. Associação Nacional de Tecnologia do Ambiente Construído - ANTAC. São Carlos. 2012.

RUBIN, Graziela Rossatto; BOLFE, Sandra Ana. O desenvolvimento da habitação social no Brasil. Ciência e Natura. v. 36, n. 2, p.202-213, 2014. http://dx.doi.org/10.5902/2179460x11637.

SANTOS, Gilles Chaves dos. Desempenho térmico de telhados verdes no agreste pernambucano. 2016. 95 f. Dissertação (Mestrado em Engenharia Civil e Ambiental) Universidade Federal de Pernambuco. Caruaru, 2016. Disponível em: <https://repositorio.ufpe.br/bitstream/123456789/25102/1/DISSERTAÇÃO\%20Gilles\%20Chaves \%20dos\%20Santos.pdf>. Acesso em: 02 mai.2019.

SAPORITO, Juliana Tancini. Análise do Programa Minha Casa Minha Vida para empreendimentos voltados para famílias classificadas na faixa 1 do programa. 2015. $117 \mathrm{f}$. Monografia (Especialização em Economia Setorial e Mercados) - Escola Politécnica da Universidade de São Paulo. São Paulo, 2015.

TRIUNFO (Município). Constituição (2006). Lei no 434/06, de 01 de junho de 2006. Código de Obras e Posturas Urbanas. Triunfo, PB,

VALENÇA, Márcio Moraes; BONATES, Mariana Fialho. The trajectory of social housing policy in Brazil: From the National Housing Bank to the Ministry of the Cities. Habitat International. v. 34, n. 2, p.165-173, abr. 2010. http://dx.doi.org/10.1016/j.habitatint.2009.08.006.

XAVIER, Alyson Lino. Estudo da utilização dos softwares energyplus e desktop radiance na cidade de cuiabá-mt. 2008. 83 f. Dissertação (Pós-Graduação em Física Ambiental) Universidade Federal de Mato Grosso. Cuiabá, 2008. 